\title{
The analysis and design of online examination system based on b/s
}

\author{
Guo-Quan Weng ${ }^{\dagger}$, Xin-Hua Zheng and Yu-Bin Zhang, \\ Ningbo Dahongying University \\ Ningbo, 315175, China \\ tE-mail: 304943282@qq.com \\ www.nbdhyu.edu.cn
}

\begin{abstract}
Nowadays, with the university expansion and the increase of students' number, traditional written examination model is still adopted by universities, colleges and social organizations. There exist many problems in written examinations, such as complex exam procedures and prone errors. With the rapid development of the era of computer application, network technology becomes more mature and improve examination quality, which facilitates students to participate in exams and feel the justice, notarization and openness. Therefore, the development of online examination system is necessary. According to the operation emphasis of online examination system, this paper will introduce functional requirements, use the diagram to express and describe through the case diagram. In the system design, this paper will elaborately design functional module by using package diagram, class diagram, sequence diagram and activity diagram and design entity class diagram adopted by database, E-R diagram and the database table structure. At last, this paper will conclude the work, point out the deficiency of the paper and make prospects for the further work.
\end{abstract}

Keywords: Online Examination; Examination Management; B/S Structure.

\section{Introduction}

Ningbo Dahongying University (DHY) will recruit 4500 students each year, among whom, freshman students are scheduled to study in the basic college. Currently, traditional examination model is adopted by DHY university. Written examination will basically need making, printing, testing and correcting[1]. During each exam, besides long cycle length, large volumes, prone errors and confidentiality work, many people, material resources and financial resources are needed, which bring great difficulties to university management and teachers' work.

American Examination Committee began to study the work of computer simulation test in the $70 \mathrm{~s}$, and the first computer examination system hadn't invented until 1983. In the early 90s, several American states began to establish degree mutual recognition teaching system, which started computer network remote test. With the form of flexibility, convenience and quickness, online 
examination has become an important examination means of foreign teaching institutions. Graduate Record Examination of American examination center is the most influential, which makes the examination can be taken on each workday instead of twice a year.

China's online education has become popular in the early $21 \mathrm{st}$, thereafter, online examination was invented, like remote network teaching platform of Zhejiang University[3]. Currently, with the constant improvement of network technology, multimedia technology[4] and database technology[5], university education is experiencing an educational reform, which will mostly adopt B/S structure[6]. National examination is slowly carried out, like Certificate of Accounting Profession has been adopting computer-based test since July 1, 2013. From which, we can find that online examination develops rapidly in China and becomes the development trend of the times.

\section{System Analysis}

\subsection{Functional Structure}

Originally online examination system mostly aims at special courses, which can only assess objective tests and automatically work out results. This examination system can meet smart groups of various question types[7], whose advantages include: a. It can separately generate examination paper and automatically generate examination paper $\mathrm{A}$ and $\mathrm{B}$, which can be used in online examination and written examination; b. It can manage client-side to design special procedures and ensure the safety of the test questions and test paper; c. It can automatically save the examine answers[4] during the online examination process and guarantee the reliability of the test by lost connection; d. It can analyze examination results and update the difficulty coefficient of examination questions; e. The examine can test themselves at any time after teachers set up the simulation tests, which can realize the basic data, question bank, examination management and other three main functions.

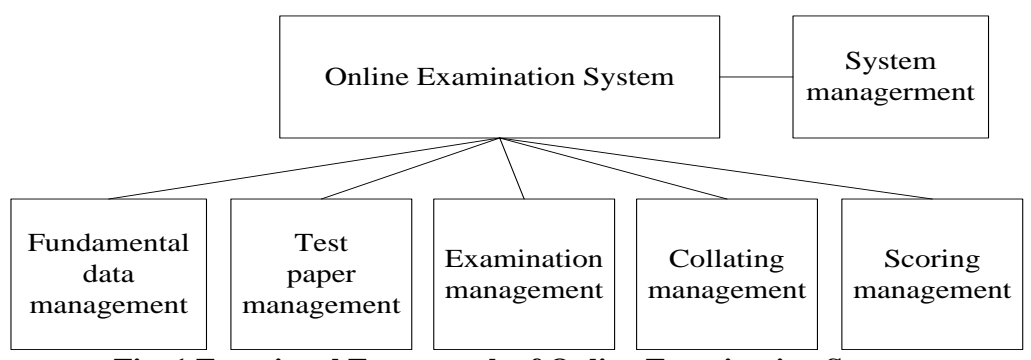

Fig. 1 Functional Framework of Online Examination System 


\subsection{B/S Structure System Architecture}

$\mathrm{B} / \mathrm{S}$ structure is mainly on the basis of most server system functions. it is effective to use the server to a user's browser client sends the request of realtime processing, and can according to the actual user's requests to the user's browser feedback web page, which standard is composed of the HTML text, the client and the script. At the same time, the web application to handle interactive function module and database[6], B/S architecture structure diagram as shown in figure 2 .

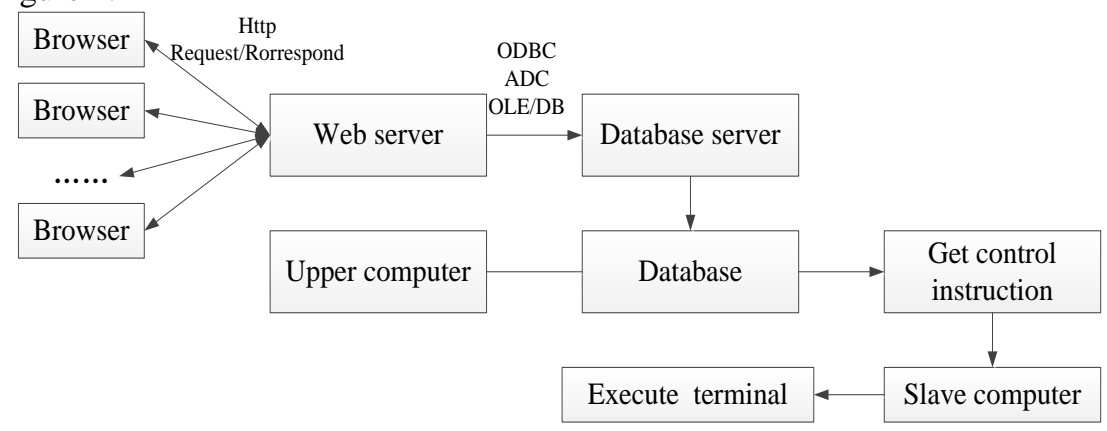

Fig. 2 Flow Chart of Online Examination System Based on B/S Structure

\section{System Design}

\subsection{System Architecture Design}

Simple three-layer B/S structure is adopted by online examination system. From top to bottom, they are respectively application layer, business layer and data later, which is shown in figure 3.

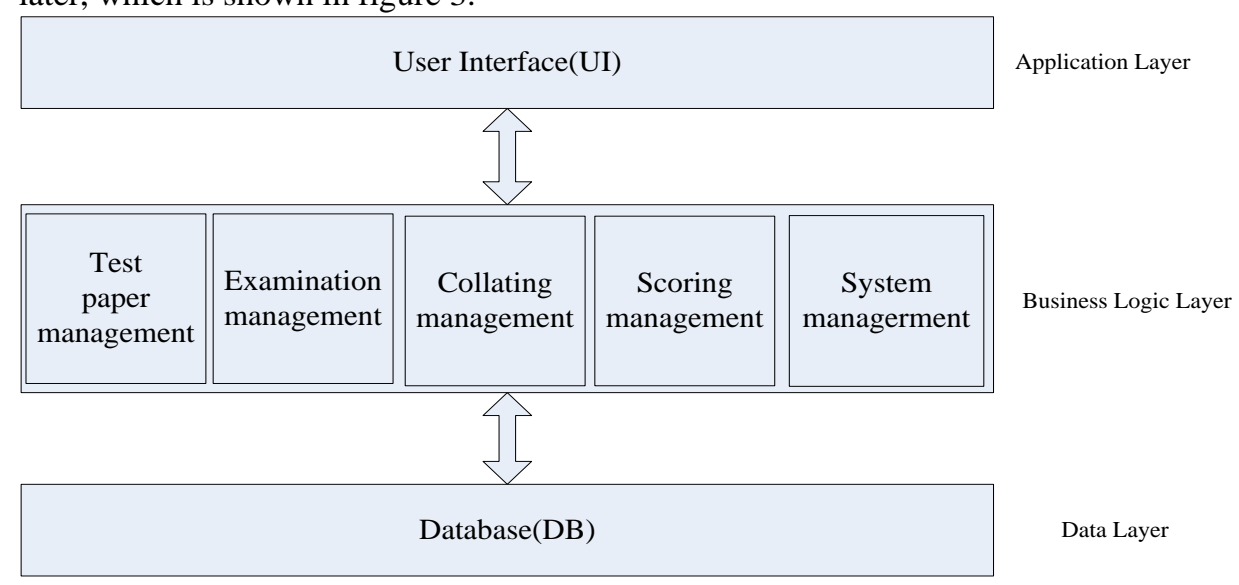

Fig 3. System Structure 
Application layer: It is responsible for the communication between the user and the system. On this layer, the user complete sending the request to the server and accept the task through the communication between the client-side and the system.

Business layer: It is the core module of online examination system, which undertakes core business of the whole online examination system. It realizes logic processing and communication of specific business through users' operation to the practical situation.

Data layer: It is the module of data operation, access and storage. It is responsible database operation, query, storage, update and other data manipulation.

Three-layer B/S structure is adopted by online examination system of Ningbo Dahongying University. Among which, business layer is used for question bank management, examination management, grading management, score management and system management.

\subsection{Data File Design}

Online examination system is required to store data, which includes examinee information, teacher information, examination questions, examination paper, examination information, performance, system settings and security information. According to their respective characteristics, examinee information, teacher information, examination questions, examination paper, examination information and performance will be stored in the form of database form, while system setting information and security information will be stored in the form of encrypted file. Taking examination question as an example, data structure is defined as examination question $=$ number + type + content + question + answer + score + difficulty coefficient + knowledge point + remark (figure 4 ).

\subsection{Intelligent Algorithm}

One of the core of online examination system is the automatic generation of the examination paper, therefore, it is important to choose a fast and effective algorithm of generating test paper. Paper constructing algorithm based on genetic algorithm is adopted in this paper. Genetic algorithm is a parallel and effective optimized algorithm, which possesses the characteristics of global optimization and fast convergence speed. Paper constructing algorithm based on genetic algorithm has all the advantages of genetic algorithm, which can well meet the requirement of automatically generating paper and effectively solve the disadvantages of random function selection method and backtracking heuristic method in paper constructing. 


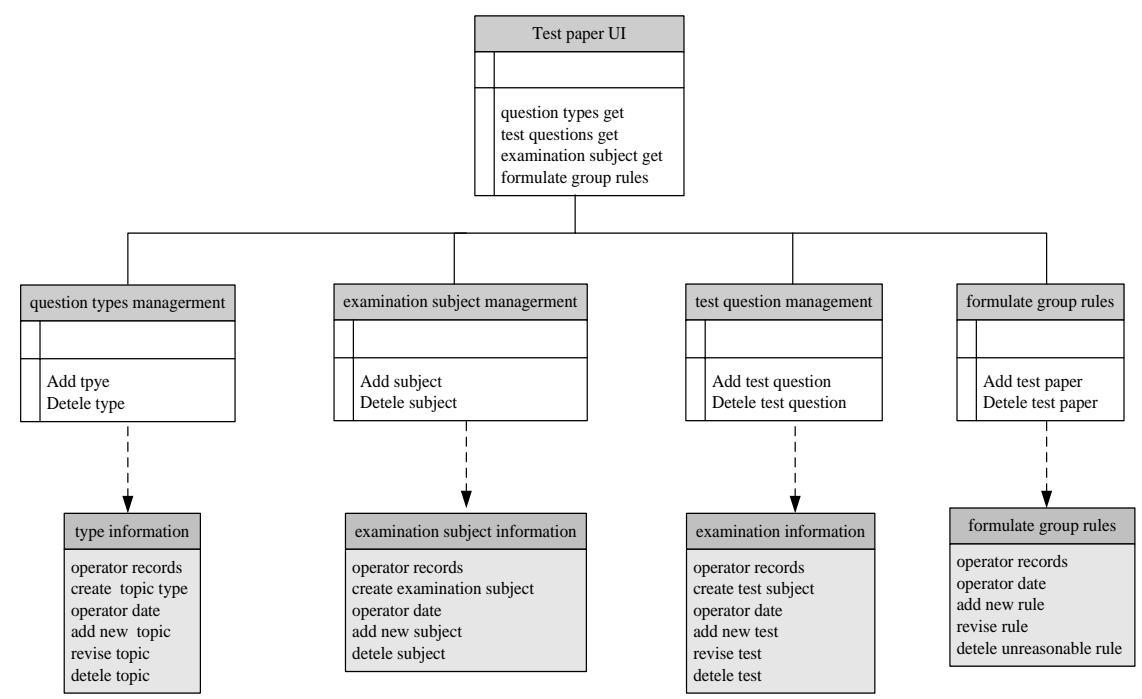

Fig 4. Test Base Management

\section{Online Examination System Development}

According to systematic functional analysis, logical model of the system can be derived. In the state of examination, examination server will respond to the examination request and start the examination process. The examinee opens the browser, $\log$ on to the examination server and enter the examination state. Data flow diagram while database server obtains the request of making out examination paper from the teacher is shown in figure 5.

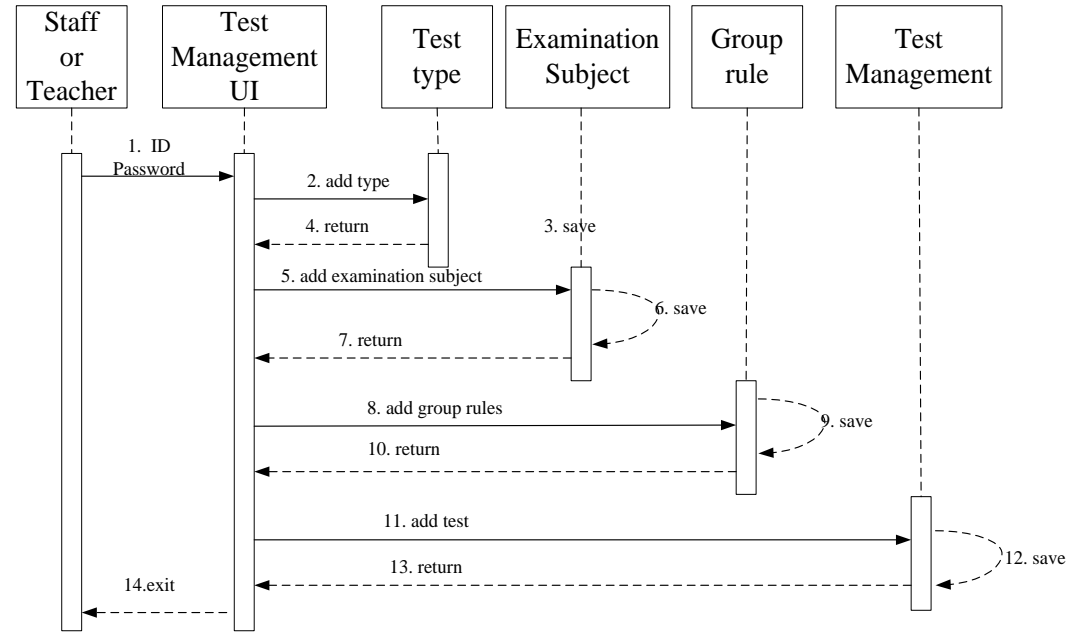

Fig 5. Sequence Diagram of Examination Base Management 


\section{5. conclusion}

The objective of online examination system discussed in this paper is to establish a smart, efficient, secure and reliable paperless examination system, which is the unity of teaching and examination. With the diversity in question type selection, the system can accommodate various disciplines, teaching, examination, which plays an important role in examination process, teaching process and excellent course construction as well as reducing the work of teachers and educational administrative staff, enhancing students' learning time and inquiring the scores conveniently.

\section{Acknowledgments}

This work was financially supported by the key project of Ningbo Da hongying university under Grant Nos. 1320151026.

\section{References}

1. Xi Luo Analysis and Design of Online Examination System in university [D], Yunnan University, 2013.4.

2. Yu Lu Design and Implementation of Online Examination System Based on Ajax Technology [D], University of Electronic Science and Technology, 2013.

3. Hongjiang Liu Design and Implementation of Online Examination System Database [J], Computer Knowledge and Technology, 2012, 8(3): 508-511.

4. Qi Li Analysis and Design of Auto Appraising Algorithm of Subjective Questions in Online Exmination [J], Journal of Wuzhou University, 2010, 20(6): 44-50.

5. Li Zhang Design and Implementation of Online Examination System Based on B/S Structure [D], Jilin University, 2014.

6. [6] Jiang Wei, Qinggui Lai, Chen Nan, et al. Implementation of DragonI database system based on B/S model [J]. High Power Laser and Particle Beams, 2010, 22 (3): 642-646.

7. Huihui Chen \& Xinyan Zhang Analysis and Design of Online Examination System [J], Computer Technology and Development, 2009, 19(10): 214217. 